\title{
Does Portfolio's Beta in Financial Market Affected by Diversification? Evidence from Amman Stock Exchange
}

\author{
Ali Matar ${ }^{1}$ \\ ${ }^{1}$ The Head of Finance and Banking Department at Jadara University, Jordan \\ Correspondence: Ali Matar, The Head of Finance and Banking Department at Jadara University, Jordan. E-mail: \\ kenoali87@yahoo.com
}

Received: August 22, 2016

Accepted: September 9, 2016 Online Published: October 27, 2016

doi:10.5539/ijbm.v11n11p101

URL: http://dx.doi.org/10.5539/ijbm.v11n11p101

\begin{abstract}
This study's goal is to examine the effect of diversification on the portfolio's beta for stocks of companies listed on the Amman Stock exchange (ASE) return over the 2005-2014 period. Moreover, it will show if the investors can reduce beta in their portfolios by diversification. Monthly data, Capital Assets Pricing Model (CAPM) and portfolio selection model were applied to measure the risk and required rate of return and compare it with the realized rate of return. The results suggest evidence that diversification can only affect unsystematic risk leaving systematic risk unaffected. The regression analysis indicates the existence of a significant relationship between the individual stock $\beta$ and the portfolio $\beta$. The results didn't approve any relationship between the portfolio size and portfolio $\beta$, and the portfolio $\beta$ is affected only by the individual stock $\beta$ value.
\end{abstract}

Keywords: portfolio, CAPM, diversification, risk, return, ASE, Jordan

\section{Introduction}

Modern portfolio theory (MPT) proposes how rational investors will use diversification to optimize their portfolios, and how risky asset should be priced. Markowitz (1952) showed that the variance of the return on a portfolio of financial securities depends not only on the riskiness of the individual securities in the portfolio, but also on the relationship among these securities, i.e., on the covariance's between the respective securities in the portfolio. He showed that the variance of a portfolio of securities might be less than the smallest variance of an individual security if there are sufficient negative covariances among the securities.

This study focuses on the Markowitz model (1952) and the Capital Asset Pricing Model (CAPM) as derived by Sharpe (1964) and Lintner (1965), which is widely used in finance to determine the appropriate required rate of return of an asset or portfolio. The CAPM formula takes into account the asset's sensitivity to non-diversifiable risk (also known as systematic risk or market risk), known as beta $(\beta)$, as well as the expected return of the market and the expected return of the risk-free asset. Therefore, this study attempts to examine the effect of diversification on the portfolio $B$ by applying the CAPM to measure the required rate of return for stocks of companies listed on the Amman Stock exchange (ASE), to compare it with the realized rate of return. Furthermore, it will show if the investors can reduce $\beta$ in their portfolios by diversification.

The main objectives of this study are:

1. Compare the required rate of return of stocks with the realized rate of return and that's to determine the market efficiency.

2. To test the effect of diversification on the portfolio $\beta$ as we increase the number of stocks in the portfolio.

Diversification is a wide aspect, and its duty to know how eliminate the unsystematic risk if we invest in a portfolio, but the question here is that: can portfolio benefits from diversification if test it on the portfolio systematic risk which is known as $\beta$ ? Therefore, this study presents a methodology, which combines two methodologies, The first one derived from Markowitz (1952) and the second one is the CAPM to test and evaluate that's questionable.

The importance of the study stems from the diversification, which has a huge impact on the portfolio riskiness, mainly on its specific risk, at which it can eliminate this risk to reach up to the systematic risk of the portfolio which known as $\beta$. Nevertheless, empirical researches in ASE ignored that whether we can reduce the portfolio $\beta$ by diversification. Therefore, this study presents the first one in Jordan that investigates the effect of diversification 
on the portfolio $\beta$ in ASE data. Based on the study's objectives, orientations and the literature review the following hypotheses can be formulated and will be investigated:

- (Efficiency Hypothesis) $\mathrm{H}_{1}$ : There is no difference between the realized rate of return of the stocks and its required rate of return.

- (Diversification Hypothesis) $\mathrm{H}_{2}$ : There is a positive relationship between the portfolio size and $\beta$ reduction.

- (Systematic Hypothesis) $\mathrm{H}_{3}$ : The benefit of diversification increases at a decreasing manner.

The remainder of this study is structured as follows: the next section presents an overview of ASE; section three introduces a brief review of the related literatures; section four explores the data and methodology; section five concludes the results analysis; and finally, conclusions and policy implications are presented in section six.

\section{An Overview of Amman Stock Exchange}

To meet the financial needs of the national economy, Jordan prides a large financial services sector and one of the oldest financial markets in the region. The ASE shares in a few publicly held companies were traded over the counter in an irregular market before the establishment of the ASE market in the late 1970s. Corporate bonds were also traded in the 1960s. To ensure quick and easy trading, collection of national savings, and protection of small investors, the ASE was established in 1978. The market grew in an unbalanced way during the 1980s and 1990s, and by the mid-1990s a further restructuring of the market was required to increase its size and liquidity. The transaction started in 1978 and operated as a regular stock exchange. Its establishment was an important innovation towards developing the financial sector in Jordan and to develop a better use of domestic and foreign financial resources through an efficient capital market. It will ease the trading to serve the financial interest of Jordan. The financial market has therefore been ranked as the frontier market. It is ranked among the top ten global emerging stock markets and one of the freest and competitive capital markets in the Middle East. It witnessed a rapid growth, especially during the last decade. The main objectives of the ASE are to develop advanced trading processes of securities, manipulating issuance, and trading of financial instruments; to provide the financial data and statistics bulletin to achieve the ASE's goals; to show contributions and performance by activating the ASE in JE; credibility in the dealing's processes of the stock market; and finally to meet the latest international standards. Public shareholding companies were established in the early 1930s while corporate bonds were issued in the sixties. Transactions were handled in individual brokerage offices. Therefore, the need for a well-organized market was stimulated and the establishment of the ASE became critical. The security's depositary centers (SDC) started operation in May 1999, as a private, nonprofit institution with financial and administrative independence run by a seven-member board of directors. The main responsibilities of SDC are to supervise the following: ownership registration of all issued shares, the task to bring about qualitative ellipses, and facilitate the cooperation between the Jordan Securities Committee (JSC) and the ASE.

Visibility and capability of the market received major regulatory attention. ASE later adopted internationally accepted trading and listing criteria. While it grew fast, in 2010 there were 277 stocks listed on the ASE with about $\$ 34$ billion in market capitalization and about $\$ 1.4$ billion in monthly trading volume1. ASE has a significant trader base not only in Jordan but also among the Middle East countries. ASE's liquidity is the fifth highest (in terms of percentage spread) (2.91\%) among the developing economies. Jordan's commerce is also increased with the West since 2001 especially in the USA. The share of exports to the United States within total exports increased from an average of 1.99\% for 1990-2000 to 22.57\% for 2001-2006 (Dicle and Khasawneh, 2010).

The number of trades shares witnessed an increase during 2010 reaching 7 billion shares, traded through 1.9 million transactions, compared with 6 billion shares traded during 2009 through 3 million transactions. The share turnover ratio also increased to reach $102.2 \%$ during the period 2010, compared with $91.3 \%$ during the period 2009. Figure (1) shows the major financial indicators of the ASE since its inception in 1978 until 2014 including the market capitalization, book value, net income, dividends, and number of subscribed shares (Bekhet and Matar, 2012). 


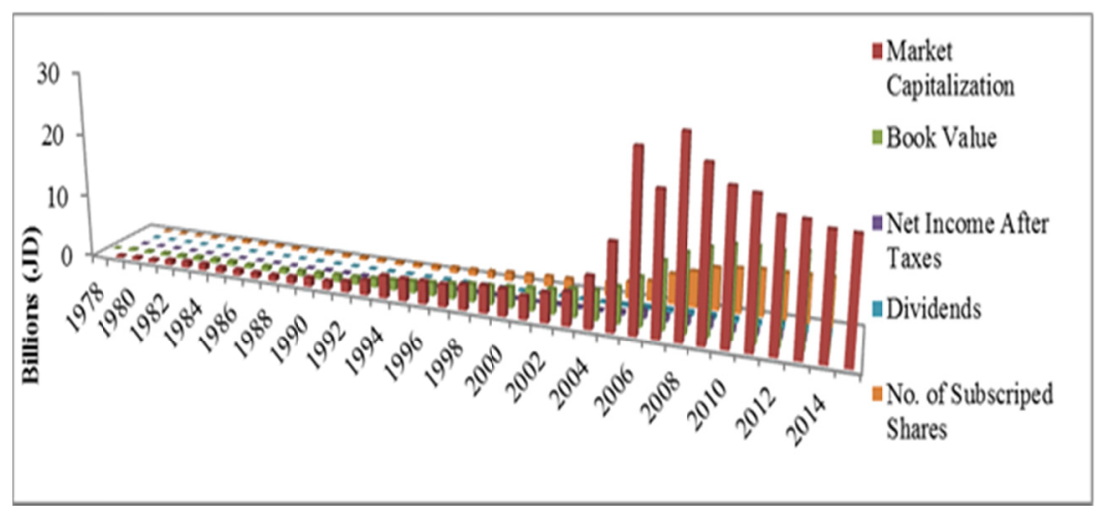

Figure 1. The major financial indicators of ASE during the 1978-2014 period

Source: ASE (2015), Major financial indicators for the ASE for the 1978-2014 period.

Figure 2 reveals that the growth rate of the ASE price index weighted by free float is 4.2 percent during the 2005-2014 period, it shows also a decrease from 2758 points to 2534 points at the end of 2008 , with the number of traded shares increasing during the period in 2009. One of the features of the Free Float Index is to give a better reflection of the changes of stock prices in the market by not being biased to the companies that have a large market capitalization. This provides diversification in the index sample by giving better chances to small and medium companies to reflect the index (http://www.ase.com.jo/).

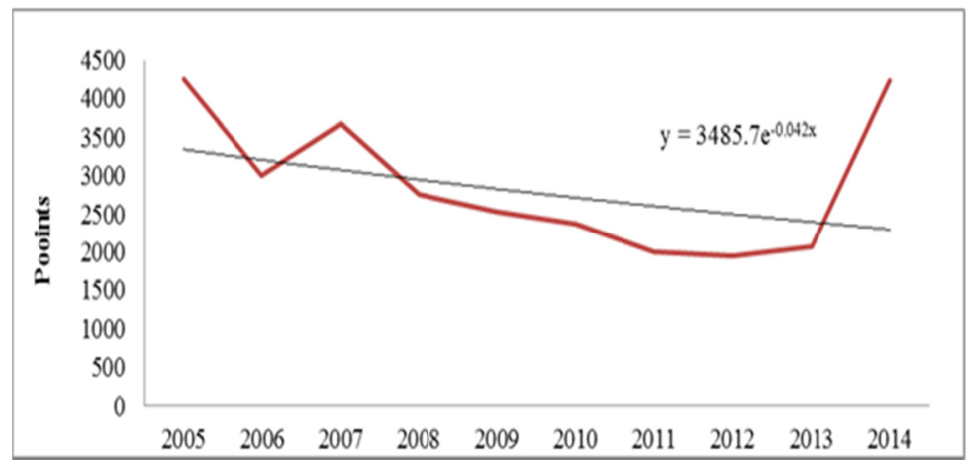

Figure 2. ASE general free float weighted price index

Source: ASE (2015), Key Statistics of the ASE available on http://www.ase.com.jo/

\section{Literature Review}

Lau et al. (1974), examined if the CAPM was applicable to Tokyo Stock Exchange (TSE) over the October 1964 to September 1969 period. Data of the study obtained from Nikko Securities of Japan, which covers all the companies on the first section of the Japan Stock Exchange (JSE). The methodology depends on the regression model for the analysis. The results showed that the CAPM is applicable to JSE. Omet (2002) suggested that the uses of monthly returns were better than two-monthly, three-monthly, four-month, and five-monthly returns in the estimation of beta because they result in the smallest standard error in the beta estimates in ASE.

Al-Fayyoumi (2003) suggested that the conditional volatility was the prime feature of daily returns behavior of these indices. Moreover, the expected returns are shown to have a positive relationship with time-varying volatility for all indices. However, the only statistically significant relationship was presented in the service index. Elsas et al. (2003) concluded that the systematic risk of a stock as measured by its market model beta is indeed a relevant measure of risk and provided a justification for the use of betas estimated from historical return data by portfolio managers. Odabasi (2003) investigated the beta stability on the Istanbul Stock Exchange (ISE) for the January 1992-December 1999. He employed different sets of data over various estimation periods and return intervals and observing the changes in beta estimates on a sample of 100 stocks. The results suggested that diversification and 
beta stability are positively correlated. Also the assessment of next-period beta becomes reliable for portfolios with ten or more stocks.

In their study, Tang and Shum (2003) showed that when the conditional relationship between beta and returns is considered, a significantly positive (negative) relationship with up (down) markets was observed. Both skewness and total risk play a significant role in pricing the risky assets. In addition, their results supported that investors prefer positive skewness, but ask for compensation for bearing higher unsystematic risk and total risk, providing evidence that international investors do not hold well-diversified portfolios. In another different study, Tang and Shum (2003) explored the conditional relationship between beta and returns in international stock markets for the January 1991 to December 2000 period. The results suggested that beta is still a useful risk measure for portfolio managers in making optimal investment decisions.

Hassan et al. (2003) showed that country political, financial and economic risks significantly determined stock volatility and predictability. Furthermore, the diversification exercise showed that the international investor can still benefit by diversifying into the stock markets of the Middle East and African countries. By using the GARCH model, Maghyereh (2003) explored the relationship between the expected return and risk in the ASE over the 1994-2000 period. The results showed that there was a significant relationship between expected return and risk in this market during the study period. Based on the methodology of Markowitz Model (1952), Al-Qudah et al. (2004) examined the effect of diversification on the portfolio risks in the ASE over the 1996-2001 period. The results approved the existence of a significant statistical relationship between portfolio size and the risk reduction. However, the t-test stated that the significant reduction benefits of diversification were virtually exhausted when a portfolio contains 10-15 stocks. Tang and Shum (2004) examined the risk-return relations in the Singapore Stock Exchange through the 1986-1998 period by using monthly returns of 144 stocks. The results indicated that other stock characteristics in addition to the beta are also important in pricing risky assets and investors do not hold diversified portfolios.

Meric et al. (2006) showed that in a bear market, the sectors of different countries tend to be more closely correlated and country diversification opportunities were limited. In a bull market, investors can obtain more benefit with global diversification than with domestic diversification even if they invest in the same sector in different countries. Kumar (2007) investigated whether the diverse choices of individual investors influence stock returns for the U.S. brokerage house through the period 1991-1996. The study used the multifactor model estimation framework. The results showed that return sensitivity to investors' diversification choices is stronger among firms that are smaller, have low institutional ownership, and are more difficult to arbitrage. Morelli (2007) examined the role of beta, size and book-to-market equity as competing risk measurements in explaining the cross-sectional returns of UK securities through the period 1980-2000. The results showed that there is a significant relationship between beta and returns even in the presence of size and book-to market equity.

Omran (2007) investigated the validity of modern portfolio theory and the capital asset pricing model in the Egyptian stock market over the 2001-2002 period. The results indicated that a portfolio that was based on consumer staples and financial companies (mainly banks) with low betas had outperformed a portfolio containing construction, materials, hotels, and weaving companies with larger betas. Frazzini and Pedersen (2014) presented a model with leverage and margin constraints that vary across investors and time. They found that short high-beta assets and long leveraged low-beta assets produced significant positive risk-adjusted returns. Besides, they argued that more constrained investors hold riskier assets.

Yalcin et al., (2011) found that the conditional CAPM fairs no better than the static counterpart in pricing assets. In addition, market betas do vary significantly over time; the inter-temporal variation is not nearly large enough to drive average conditional alphas to zero. Al Bakri (2014) identified the impact of portfolio diversification on the generated property company's stock returns and the real estate industry performance and risk in the Middle East. The results showed that there is no distinct relationship between the number of real estate assets held in the portfolio and expected return. Furthermore, the principle of diversification has nothing to do with the returns that the real estate assets in the portfolio generate together. Richard and Roncalli (2015) analyzed the relationship between risk diversification and volatility reduction. The results suggested that the smart betas portfolios differ because the implicit target different levels of volatility reduction. Besides, they developed new smart beta strategies by managing the level of volatility reduction similar to the constrained minimum variance model.

\section{Data Sources and Methodology}

To examine the effect of diversification on the portfolio beta $(\beta)$, as the number of stocks in the portfolio increase, monthly closing prices of randomly selected companies listed in ASE, ASE index, and the Central Bank of Jordan 6-month Certificate of Deposits monthly returns as a measure of the risk-free investment will be used, over the 
time period 2005 to 2014.

\subsection{Data Source and Sample}

The data for the study were collected from the publications and home pages of ASE and the Central Bank of Jordan.

The study is based on the risk and return data of a sample of 112 stocks listed in ASE, the selected sample fulfil the following conditions:

1. Companies listed on the ASE market during the period of this study.

2. All companies share the same fiscal year, ending on 31 December of each year.

3. Companies having no change in position (e.g. Mergers, stock split, and suspension of trade).

The number of total listed companies and of stocks sample in each category in ASE is given in Table (4-1).

Table1. Representation of sample stocks

\begin{tabular}{llll}
\hline Description & NO. of listed Co. & Sample Co. & Proportion \\
\hline Commercial Bank & 15 & 11 & $9.822 \%$ \\
& & & $5 \%$ \\
Insurance Companies & 26 & 21 & $18.750 \%$ \\
Services Companies & 97 & 25 & $22.321 \%$ \\
Industrial Companies & 90 & 55 & $49.107 \%$ \\
Total & $\mathbf{2 2 8}$ & $\mathbf{1 1 2}$ & $\mathbf{1 0 0 \%}$ \\
\hline
\end{tabular}

\subsection{Methodology}

The current study attempts to analyze the effect of diversification on the portfolio $\beta$. The methodology implemented consists of analyzing a sample of 112 companies listed on the ASE during the study period. Since Al-Qudah et al. (2004) examined the effect of diversification on the portfolio unsystematic risk; this study examines that if the mechanism of diversification can be applied on the portfolio $\beta$. The methodology of the study is based upon applying two models: The first one derived from Markowitz (1952) and the second one is the CAPM as derived by Sharpe (1964) and Lintner (1965).

The actual (realized) returns on each stock as well as on the market index calculated as follows:

$$
R_{i, t}=\frac{P_{i, t+1}-P_{i, t}}{P_{i, t}}
$$

Where $R_{i, t}$ is the realized return on a stock i at time $\mathrm{t} ; P_{i, t}:$ is the closing price of the stock i at time $\mathrm{t} ; P_{i, t+1}$ is the closing price of the stock $\mathrm{i}$ at time $\mathrm{t}+1$. Assuming equally weighted portfolios, the average rate of return of each stock over the study period (10 years) was:

$$
\bar{R}_{i}=\frac{\sum_{t=1}^{n} R_{i, t}}{n}
$$

Where $\bar{R}_{i}$ : is the average rate of return for stock $i ; R i, t:$ is the monthly rate of return for stock $i ; n$ : is the number of the holding period of the stock $i$. Since we are interested in portfolio $\beta$ rather than $\beta$ of an individual security, the process of calculating $\beta$ becomes more difficult. To find the portfolio $\beta$, the sample covariance was estimated between stocks and the market, by the following formula:

$$
\operatorname{Cov} r_{i}, r_{m}=\frac{\sum_{t=1}^{n}\left[\left(r_{i, t}-\bar{r}_{i}\right)\left(r_{m, t}-\bar{r}_{m}\right)\right]}{n-1}
$$

Where: $n$ is the number of observations (periods); $r_{i, t}$ is the rate of return for stock $\mathrm{i}$ at the time $\mathrm{t} ; \overline{r_{i}}$ is the average rate of return for stock $i ; r_{m, t}$ is the rate of return for the market at the time t. $\overline{r_{m}}$ is the average rate of return for the market. The market risk $\left(\sigma^{2} r_{m}\right)$ calculated by the sample-variance formula: 


$$
\sigma^{2} r_{m}=\frac{\sum_{t=1}^{n}\left(r_{m}-\bar{r}_{m}\right)^{2}}{n-1}
$$

Where: $\sigma^{2} r_{m}$ is the variance of the market portfolio; $r_{m}$ is the market rate of return at the time $t$.

$\bar{r}_{M}$ is the average rate of return for the market; $n$ is the number of periods.

The risk for the stock $i$ can be tested by using the (5) model, while the risk of a portfolio is given by formula (6):

$$
\begin{aligned}
\sigma_{r i}^{2} & =\frac{\sum_{t=1}^{n}\left(r_{i, t+1}-\bar{r}_{i}\right)^{2}}{n-1} \\
\sigma^{2}\left(r_{p}\right) & =\sum_{i=1}^{n} w_{i}^{2} \sigma\left(r_{i}\right)+\sum_{i=1}^{n} \frac{\sum_{j=1}^{n}\left(w_{i}\right)\left(w_{j}\right) \rho_{i, j} \sigma\left(r_{i}\right) \sigma\left(r_{j}\right)}{}
\end{aligned}
$$

Where: $\sigma^{2} r_{i}$ is the variance of stock $i . r_{i, t+1}$ is the return on stock $i$ in the month $t+1 ; \overline{r_{i}}$ is the average rate of return for stock $i ; n$ is the number of holding months of stock $i ; \sigma^{2} r_{p}$ is the variance of the return in the portfolio; $w_{i, j}$ is the proportion (weight) of invested funds in each of the securities $i$ and $j$ in the portfolio; $\rho_{i, j}$ is the correlation coefficient which measures the extent to which the returns on securities $i$ and $j$ are linearly related; and $\sigma$ is the standard deviation of securities $i$ and $j$.

After the results obtained from all previous calculations, $\beta$ was calculated for each stock by the following model:

$$
\beta_{i}=\frac{\operatorname{Cov} r_{i}, r_{m}}{\sigma^{2} r_{m}}
$$

Subsequently, the required rate of return $(R R)$ calculated for each stock by using the CAPM formula:

$$
R R=R_{f}+\beta_{i}\left(R_{m}+R_{f}\right)
$$

Where: $R R$ is the minimum required rate of return of the stock $i$. $R_{f}$ is the risk-free rate of interest. $R_{m}$ is the expected return on the market Portfolio. $\beta_{i}$ is the measure of systematic risk of stock $i$.

The final step in this methodology based upon making a randomize and planned selection among stocks, and formulating several portfolios with different sizes, then calculating $\beta$ for each portfolio, and that to test the effect of diversification on its betas. The calculation done by using the following formula:

$$
\beta_{p}=\frac{\sum \beta_{i}}{w}
$$

Where: $\beta_{p}$ is the portfolio beta; $\beta_{i}$ is the average systematic risk of stock $i$; $w$ is the number of stocks invested in the portfolio.

To trace the relationship between diversification and the portfolio $\beta .112$ portfolios with different sizes ranging from one stock to 112 stocks have been generated, and two selection methods were followed. The first method based on the randomize selection, and the second one based on a planned selection. In the randomize selection method, all stocks were sorted ascending according the alphabetical manner. Where, the first stock was put in portfolio one, and then, the second stock added to the first portfolio to formulate portfolio two, also the third stock added to the portfolio two to formulate the portfolio three, and that's so on to portfolio 112. In the planned selection all stocks were sorted ascending from the lowest $\beta$ stock to the highest $\beta$ stock. Where, the lowest $\beta$ stock was put in the portfolio one, and by adding the second lowest $\beta$ stock to portfolio one portfolio two was formulated. Then this process continued up to the portfolio 112. The total simulated portfolio were (224) portfolios, for each simulated portfolio, $\beta$ was calculated. Before starting the examination of hypotheses, normality test was conducted to test the normality of the mean rate of returns. Then the portfolios simulated were examined by using the regression analysis as shown in the following formula.

$$
Y_{i}=B_{i}\left(1 / X_{i}\right)+A
$$

Where: $X_{i}$ the independent variable (individual stock $\beta$ ); $Y_{i}$ the dependent variable (computed portfolio $\beta$ at each level of $X_{i}$ ). 


\section{Results Analysis}

The main objective of this study is to examine the rate at which portfolio's beta is reduced as a function of the number of securities included in the portfolio. In order to prove the hypotheses generated, we have conducted a primary analysis, monthly arithmetic mean rate of return, monthly arithmetic mean required rates of return, and betas. We consider monthly returns rather than annual returns because investors and portfolio managers are more likely to perform some rebalancing of their portfolios at monthly rather than annual intervals. Also, we consider monthly returns rather than weekly returns, because of the thin trading problem in many stocks at ASE. The mean rate rates of return, mean required return, and betas of (112)-stocks included in the analysis over the study period, were computed according to formulas (2), (7), and (8) mentioned in section four. The results obtained by using Excel and SPSS, (20) are summarized in Table 1.

The contents of the table represent a descriptive analysis of the (112) stock prices included in the analysis. Since the mean rates of returns are considered the most important data input, which needed for all subsequent analysis, so it is necessary to verify the outliers that may affect the results obtained, as well as, testing the normality of these returns. In Table 1 the descriptive summary of the (112) stocks mean rate of return. Table 3 summarizes the most important parameters of stocks return, which describe the distribution of stocks return. By assumption, if the number of observations is greater than 30 and the period of study is long enough, a normal distribution is expected, (Central Limit Theorem). If investors were observed the monthly return on a typical stock over a period of time, the frequency distribution of returns would not depart significantly from that of a normal distribution (Haugen, 2001). Therefore, we can conclude that stock returns have an asymmetric normal distribution of stocks return skewed to the right (positive skewness). Also kurtosis indicates that the distribution of stock returns has tails higher than that of a normal distribution, tails approach zero slower than that of a normal distribution.

Table 2. Descriptive statistics

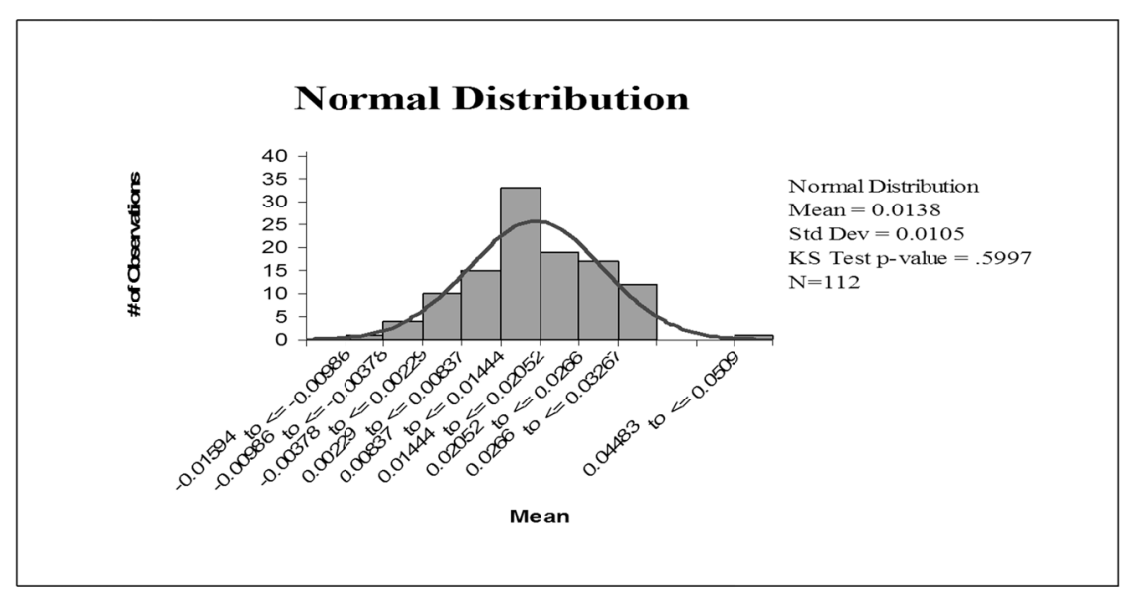

\begin{tabular}{l|l} 
Mean & 0.0138 \\
\hline Maximum & 0.0509 \\
\hline Minimum & -0.0159 \\
\hline Variance & 0.0001 \\
\hline Standard deviation & 0.0105 \\
\hline Skewness & 0.15 \\
\hline Kurtosis & 0.70
\end{tabular}

\subsection{Hypotheses Testing}

The aim of the above analysis was preliminary in order to test the hypothesis generated:

- (Efficiency Hypothesis) $\mathrm{H}_{1}$ : There is no difference between the realized rate of return of the stocks and its required rate of return.

- (Diversification Hypothesis) $\mathrm{H}_{2}$ : There is a positive relationship between the portfolio size and $\beta$ reduction.

- (Systematic Hypothesis) $\mathrm{H}_{3}$ : The benefit of diversification increases at a decreasing manner.

The next important step involved comparing the realized rate of return for each stock with the required rate of return as computed by the CAPM to examine the similarity between the two returns and to determine the market efficiency. To examine this similarity, monthly realized return for each stock subtracted from the monthly required rate of return. The final results obtained through this comparison, are illustrated in Table 4 . Table 4 illustrates the differentials between the required rate of return and the realized rates of return for each stock included in the study. As shown in the above table all stocks generated a realized rate of return below its required rate of return except stocks of $6,7,10,11,18,36,38,42,50,53,54,55,56,88,89$, and 101 , these stocks generated a realized rate of return above its required rate of return, as a percentage of $14.2 \%$ of the total sample included in the analysis. 
Therefore, we can conclude that the most stocks are undervalued, and ASE is an inefficient market.

The next step in testing hypothesis involved computing $\beta$ for each portfolio generated to determine the relationship between the portfolio size and the portfolio $\beta$. To examine this relationship, a two selection methods were followed. The first method involved a randomize portfolio selection, and the second one based on a planned portfolio selection. In the randomize selection, all stocks were sorted ascending according the alphabetical manner. Where, the first stock was put in portfolio one, and then, the second stock added to the first stock to formulate portfolio two, also the third stock added to the portfolio two to formulate the portfolio three, and that's so on to portfolio 112 . After that, $\beta$ was calculated for each portfolio. In the planned selection all stocks were sorted ascending from the lowest $\beta$ stock to the highest $\beta$ stock. And also 112 portfolios were formulated, where, the lowest $\beta$ stock was put in the portfolio one, and by adding the second lowest $\beta$ stock to portfolio one portfolio two was formulated. Then this process continued up to the portfolio 112. Also portfolios $\beta$ was calculated for each portfolio. The results obtained, are illustrated in Table 5.

Table 3. Stocks return and beta analysis over the (1/1/2005-31/12/2014) period

\begin{tabular}{|c|c|c|c|c|c|c|}
\hline \multicolumn{4}{|c|}{ Stock CodeMean ReturnMean Required ReturnBeta } & \multicolumn{3}{|c|}{ Stock CodeMean ReturnMean Required ReturnBeta } \\
\hline 1 & 0.0140 & 0.0210 & 0.881657 & 0.0098 & 0.0231 & 0.8050 \\
\hline 2 & 0.0102 & 0.0225 & 0.824558 & 0.0110 & 0.0338 & 0.4156 \\
\hline 3 & 0.0211 & 0.0220 & 0.845759 & 0.0177 & 0.0303 & 0.5444 \\
\hline 4 & 0.0138 & 0.0173 & 1.014660 & 0.0072 & 0.0333 & 0.4332 \\
\hline 5 & 0.0139 & 0.0225 & 0.826461 & 0.0126 & 0.0326 & 0.4585 \\
\hline 6 & 0.0210 & 0.0159 & 1.067562 & 0.0258 & 0.0393 & 0.2183 \\
\hline 7 & 0.0198 & 0.0178 & 0.998363 & 0.0006 & 0.0451 & 0.0048 \\
\hline 8 & 0.0249 & 0.0265 & 0.681364 & 0.0002 & 0.0437 & 0.0567 \\
\hline 9 & 0.0227 & 0.0278 & 0.632665 & 0.0191 & 0.0221 & 0.8418 \\
\hline 10 & 0.0212 & 0.0138 & 1.143266 & -0.0066 & 0.0394 & 0.2136 \\
\hline 11 & 0.0271 & 0.0165 & 1.043067 & 0.0132 & 0.0341 & 0.4050 \\
\hline 12 & 0.0177 & 0.0433 & 0.069968 & 0.0024 & 0.0325 & 0.4651 \\
\hline 13 & 0.0072 & 0.0313 & 0.505569 & 0.0111 & 0.0388 & 0.2339 \\
\hline 14 & 0.0088 & 0.0361 & 0.331770 & 0.0193 & 0.0268 & 0.6716 \\
\hline 15 & 0.0100 & 0.0327 & 0.455671 & 0.0130 & 0.0356 & 0.3515 \\
\hline 16 & 0.0143 & 0.0309 & 0.520272 & 0.0091 & 0.0431 & 0.0783 \\
\hline 17 & 0.0091 & 0.0182 & 0.983473 & 0.0324 & 0.0331 & 0.4407 \\
\hline 18 & 0.0222 & 0.0170 & 1.027274 & 0.0115 & 0.0264 & 0.6853 \\
\hline 19 & 0.0208 & 0.0345 & 0.389675 & -0.0023 & 0.0367 & 0.3124 \\
\hline 20 & 0.0055 & 0.0375 & 0.280876 & -0.0003 & 0.0341 & 0.4054 \\
\hline 21 & 0.0159 & 0.0399 & 0.193677 & -0.0037 & 0.0404 & 0.1758 \\
\hline 22 & 0.0087 & 0.0447 & 0.019078 & 0.0309 & 0.0330 & 0.4439 \\
\hline 23 & 0.0104 & 0.0305 & 0.537679 & 0.0134 & 0.0270 & 0.6612 \\
\hline 24 & 0.0173 & 0.0402 & 0.185680 & 0.0019 & 0.0356 & 0.3498 \\
\hline 25 & 0.0052 & 0.0300 & 0.556081 & 0.0111 & 0.0269 & 0.6683 \\
\hline 26 & -0.0159 & 0.0431 & 0.078982 & 0.0277 & 0.0355 & 0.3553 \\
\hline 27 & 0.0058 & 0.0230 & 0.806983 & 0.0194 & 0.0347 & 0.3851 \\
\hline 28 & 0.0025 & 0.0257 & 0.711284 & 0.0025 & 0.0388 & 0.2350 \\
\hline 29 & 0.0157 & 0.0401 & 0.186985 & 0.0177 & 0.0190 & 0.9535 \\
\hline 30 & -0.0007 & 0.0448 & 0.018986 & 0.0297 & 0.0413 & 0.1457 \\
\hline 31 & 0.0092 & 0.0322 & 0.475387 & -0.0065 & 0.0437 & 0.0579 \\
\hline 32 & 0.0164 & 0.0237 & 0.782588 & 0.0252 & 0.0109 & 1.2475 \\
\hline 33 & 0.0096 & 0.0324 & 0.467789 & 0.0289 & 0.0265 & 0.6824 \\
\hline 34 & 0.0054 & 0.0332 & 0.437990 & 0.0071 & 0.0423 & 0.1068 \\
\hline 35 & 0.0142 & 0.0374 & 0.284391 & 0.0142 & 0.0307 & 0.5273 \\
\hline 36 & 0.0509 & 0.0153 & 1.087592 & 0.0266 & 0.0273 & 0.6509 \\
\hline 37 & 0.0036 & 0.0253 & 0.724893 & 0.0104 & 0.0335 & 0.4262 \\
\hline 38 & 0.0217 & 0.0206 & 0.896094 & -0.0009 & 0.0449 & 0.0133 \\
\hline 39 & 0.0235 & 0.0304 & 0.538495 & 0.0190 & 0.0273 & 0.6516 \\
\hline 40 & 0.0129 & 0.0342 & 0.400996 & 0.0140 & 0.0387 & 0.2397 \\
\hline
\end{tabular}




\begin{tabular}{lllllll}
\hline 41 & 0.0207 & 0.0238 & 0.778997 & 0.0048 & 0.0392 & 0.2188 \\
42 & 0.0156 & 0.0127 & 1.181098 & 0.0165 & 0.0294 & 0.5768 \\
43 & -0.0074 & 0.0426 & 0.098799 & 0.0322 & 0.0425 & 0.1008 \\
44 & 0.0031 & 0.0442 & 0.0376100 & -0.0044 & 0.0434 & 0.0685 \\
45 & 0.0282 & 0.0353 & 0.3624101 & 0.0316 & 0.0300 & 0.5548 \\
46 & 0.0008 & 0.0351 & 0.3701102 & 0.0160 & 0.0390 & 0.2276 \\
47 & 0.0067 & 0.0267 & 0.6728103 & 0.0130 & 0.0308 & 0.5245 \\
48 & 0.0218 & 0.0379 & 0.2685104 & 0.0180 & 0.0385 & 0.2456 \\
49 & 0.0091 & 0.0263 & 0.6884105 & 0.0182 & 0.0439 & 0.0512 \\
50 & 0.0255 & 0.0164 & 1.0476106 & 0.0111 & 0.0217 & 0.8556 \\
51 & 0.0147 & 0.0256 & 0.7137107 & 0.0250 & 0.0378 & 0.2712 \\
52 & 0.0159 & 0.0229 & 0.8127108 & 0.0121 & 0.0279 & 0.6314 \\
53 & 0.0308 & 0.0040 & 1.4989109 & 0.0006 & 0.0452 & 0.0021 \\
54 & 0.0292 & 0.0226 & 0.8237110 & 0.0056 & 0.0314 & 0.5030 \\
55 & 0.0312 & 0.0098 & 1.2867111 & 0.0121 & 0.0402 & 0.1828 \\
56 & 0.0210 & 0.0111 & 1.2394112 & 0.0144 & 0.0367 & 0.3121 \\
\hline
\end{tabular}

Table 4. Differentials between stocks required return and realized return

\begin{tabular}{|c|c|c|c|c|c|c|c|}
\hline \multirow[b]{2}{*}{ Stock Code } & \multirow[b]{2}{*}{ Required Return } & \multicolumn{3}{|l|}{ Realized } & \multirow[b]{2}{*}{ Required Return } & \multicolumn{2}{|l|}{ Realized } \\
\hline & & Return & Differentials & Stock Code & & Return & Differentials \\
\hline 1 & 0.0210 & 0.0140 & 0.0070 & 57 & 0.0231 & 0.0098 & 0.0133 \\
\hline 2 & 0.0225 & 0.0102 & 0.0123 & 58 & 0.0338 & 0.0110 & 0.0228 \\
\hline 3 & 0.0220 & 0.0211 & 0.0009 & 59 & 0.0303 & 0.0177 & 0.0126 \\
\hline 4 & 0.0173 & 0.0138 & 0.0035 & 60 & 0.0333 & 0.0072 & 0.0261 \\
\hline 5 & 0.0225 & 0.0139 & 0.0086 & 61 & 0.0326 & 0.0126 & 0.0200 \\
\hline 6 & 0.0159 & 0.0210 & -0.0051 & 62 & 0.0393 & 0.0258 & 0.0134 \\
\hline 7 & 0.0178 & 0.0198 & -0.0020 & 63 & 0.0451 & 0.0006 & 0.0446 \\
\hline 8 & 0.0265 & 0.0249 & 0.0016 & 64 & 0.0437 & 0.0002 & 0.0435 \\
\hline 9 & 0.0278 & 0.0227 & 0.0052 & 65 & 0.0221 & 0.0191 & 0.0029 \\
\hline 10 & 0.0138 & 0.0212 & -0.0074 & 66 & 0.0394 & -0.0066 & 0.0460 \\
\hline 11 & 0.0165 & 0.0271 & -0.0105 & 67 & 0.0341 & 0.0132 & 0.0209 \\
\hline 12 & 0.0433 & 0.0177 & 0.0256 & 68 & 0.0325 & 0.0024 & 0.0300 \\
\hline 13 & 0.0313 & 0.0072 & 0.0241 & 69 & 0.0388 & 0.0111 & 0.0277 \\
\hline 14 & 0.0361 & 0.0088 & 0.0273 & 70 & 0.0268 & 0.0193 & 0.0074 \\
\hline 15 & 0.0327 & 0.0100 & 0.0227 & 71 & 0.0356 & 0.0130 & 0.0226 \\
\hline 16 & 0.0309 & 0.0143 & 0.0166 & 72 & 0.0431 & 0.0091 & 0.0340 \\
\hline 17 & 0.0182 & 0.0091 & 0.0091 & 73 & 0.0331 & 0.0324 & 0.0008 \\
\hline 18 & 0.0170 & 0.0222 & -0.0052 & 74 & 0.0264 & 0.0115 & 0.0149 \\
\hline 19 & 0.0345 & 0.0208 & 0.0137 & 75 & 0.0367 & -0.0023 & 0.0390 \\
\hline 20 & 0.0375 & 0.0055 & 0.0321 & 76 & 0.0341 & -0.0003 & 0.0344 \\
\hline 21 & 0.0399 & 0.0159 & 0.0240 & 77 & 0.0404 & -0.0037 & 0.0441 \\
\hline 22 & 0.0447 & 0.0087 & 0.0360 & 78 & 0.0330 & 0.0309 & 0.0021 \\
\hline 23 & 0.0305 & 0.0104 & 0.0201 & 79 & 0.0270 & 0.0134 & 0.0136 \\
\hline 24 & 0.0402 & 0.0173 & 0.0229 & 80 & 0.0356 & 0.0019 & 0.0338 \\
\hline 25 & 0.0300 & 0.0052 & 0.0247 & 81 & 0.0269 & 0.0111 & 0.0158 \\
\hline 26 & 0.0431 & -0.0159 & 0.0590 & 82 & 0.0355 & 0.0277 & 0.0078 \\
\hline
\end{tabular}




\begin{tabular}{|c|c|c|c|c|c|c|c|}
\hline 27 & 0.0230 & 0.0058 & 0.0173 & 83 & 0.0347 & 0.0194 & 0.0153 \\
\hline 28 & 0.0257 & 0.0025 & 0.0232 & 84 & 0.0388 & 0.0025 & 0.0363 \\
\hline 29 & 0.0401 & 0.0157 & 0.0244 & 85 & 0.0190 & 0.0177 & 0.0012 \\
\hline 30 & 0.0448 & -0.0007 & 0.0454 & 86 & 0.0413 & 0.0297 & 0.0116 \\
\hline 31 & 0.0322 & 0.0092 & 0.0230 & 87 & 0.0437 & -0.0065 & 0.0502 \\
\hline 32 & 0.0237 & 0.0164 & 0.0073 & 88 & 0.0109 & 0.0252 & -0.0143 \\
\hline 33 & 0.0324 & 0.0096 & 0.0228 & 89 & 0.0265 & 0.0289 & -0.0024 \\
\hline 34 & 0.0332 & 0.0054 & 0.0278 & 90 & 0.0423 & 0.0071 & 0.0352 \\
\hline 35 & 0.0374 & 0.0142 & 0.0233 & 91 & 0.0307 & 0.0142 & 0.0166 \\
\hline 36 & 0.0153 & 0.0509 & -0.0356 & 92 & 0.0273 & 0.0266 & 0.0008 \\
\hline 37 & 0.0253 & 0.0036 & 0.0217 & 93 & 0.0335 & 0.0104 & 0.0232 \\
\hline 38 & 0.0206 & 0.0217 & -0.0012 & 94 & 0.0449 & -0.0009 & 0.0458 \\
\hline 39 & 0.0304 & 0.0235 & 0.0069 & 95 & 0.0273 & 0.0190 & 0.0083 \\
\hline 40 & 0.0342 & 0.0129 & 0.0213 & 96 & 0.0387 & 0.0140 & 0.0247 \\
\hline 41 & 0.0238 & 0.0207 & 0.0031 & 97 & 0.0392 & 0.0048 & 0.0345 \\
\hline 42 & 0.0127 & 0.0156 & -0.0029 & 98 & 0.0294 & 0.0165 & 0.0128 \\
\hline 43 & 0.0426 & -0.0074 & 0.0499 & 99 & 0.0425 & 0.0322 & 0.0103 \\
\hline 44 & 0.0442 & 0.0031 & 0.0411 & 100 & 0.0434 & -0.0044 & 0.0478 \\
\hline 45 & 0.0353 & 0.0282 & 0.0071 & 101 & 0.0300 & 0.0316 & -0.0016 \\
\hline 46 & 0.0351 & 0.0008 & 0.0342 & 102 & 0.0390 & 0.0160 & 0.0230 \\
\hline 47 & 0.0267 & 0.0067 & 0.0200 & 103 & 0.0308 & 0.0130 & 0.0178 \\
\hline 48 & 0.0379 & 0.0218 & 0.0161 & 104 & 0.0385 & 0.0180 & 0.0205 \\
\hline 49 & 0.0263 & 0.0091 & 0.0172 & 105 & 0.0439 & 0.0182 & 0.0257 \\
\hline 50 & 0.0164 & 0.0255 & -0.0091 & 106 & 0.0217 & 0.0111 & 0.0106 \\
\hline 51 & 0.0256 & 0.0147 & 0.0109 & 107 & 0.0378 & 0.0250 & 0.0128 \\
\hline 52 & 0.0229 & 0.0159 & 0.0070 & 108 & 0.0279 & 0.0121 & 0.0158 \\
\hline 53 & 0.0040 & 0.0308 & -0.0269 & 109 & 0.0452 & 0.0006 & 0.0446 \\
\hline 54 & 0.0226 & 0.0292 & -0.0067 & 110 & 0.0314 & 0.0056 & 0.0258 \\
\hline 55 & 0.0098 & 0.0312 & -0.0214 & 111 & 0.0402 & 0.0121 & 0.0282 \\
\hline 56 & 0.0111 & 0.0210 & -0.0099 & 112 & 0.0367 & 0.0144 & 0.0222 \\
\hline
\end{tabular}

Table 5 is the essence of this study; it is simply illustrating the relationship between the number of stocks in the portfolio and the portfolio's risk as measured by $\beta$. The above table shows that as the number of securities (stocks) in the portfolio increases, the portfolio risk as measured by $\beta$ increases, if the new stock $\beta$ is higher than the portfolio $\beta$, and the portfolio risk as measured by $\beta$ decreases, if the new stock $\beta$ is lower than the portfolio $\beta$, which indicates that is no relationship between the portfolio size and portfolio $\beta$. From the above table, we can conclude that the benefit of diversification on the portfolio $\beta$ can obtained only when the new stock has a negative $\beta$ or has a $\beta$ less than the portfolio $\beta$. In addition, we can conclude that, as portfolio size increases, we can maintain the stability of the portfolio $\beta$, by a greater proportion of constant $\beta$ stocks.

However, the results in table (5-4) are not conclusive, as they involve no statistical testing. Therefore, this result is not enough to test the relationship between the individual stock $\beta$ and the portfolio $\beta$. For this purpose, a regression and correlation statistics are employed. To test the relationship between the individual stock $\beta$ and the portfolio $\beta$, regression analysis is performed according to the model (10) in the previous section. Where $Y$ (the portfolio $\beta$ ) is the dependent variable, and $X$ (the individual stock $\beta$ ) is the independent variable. This function describes a rectangular hyperbola with a positive asymptote; yields an extremely good fit, as indicated by a coefficient of 
determination of (0.9575), at a significance level (0.05). The regression results are summarized in Table 6. The regression results indicate the existence of a significant relationship between the individual stock $\beta$ and the portfolio $\beta$. Under the simple regression model with one independent variable, $\mathrm{R}$ (measure goodness of fit) equal to (0.9785), indicate nearly a perfect positive relationship, and coefficient of determination $\left(R^{2}\right)$ of $(0.9575)$ shows the proportion of total variance in the dependent variable explained by variation of the independent variable.

\subsection{Correlation Analysis}

As proved under regression analysis the existence of a significant relationship between the individual stocks $\beta$ and the portfolio $\beta$. It seems very important to have some analysis about the direction of this relationship. As a result, we conduct a Pearson correlation analysis, and we obtained a (0.979) correlation, nearly a perfect positive correlation which shows that the relationship between the individual stocks $\beta$ and the portfolio $\beta$ is a positive relation. The statistical tests implemented did prove the existence of a significant positive relationship between the portfolio risks as measured $\beta$ and the individual stocks $\beta$, and supported the result that is no relationship between the portfolio size and the portfolio $\beta$. And denied the hypothesis that the benefit from diversification in the portfolio $\beta$ increasing at a decreasing manner.

Table 5. The relationship between the number of stocks \& the portfolio $\beta$

\begin{tabular}{|c|c|c|c|c|c|c|c|}
\hline \multicolumn{4}{|c|}{ The randomize selection } & \multicolumn{4}{|l|}{ The Planned Selection } \\
\hline $\begin{array}{l}\text { No. Of Stocks In } \\
\text { The Portfolio }\end{array}$ & $\begin{array}{l}\text { Portfol } \\
\text { io } \beta\end{array}$ & $\begin{array}{l}\text { No. Of Stocks In } \\
\text { The Portfolio }\end{array}$ & $\begin{array}{l}\text { Portfol } \\
\text { io } \beta\end{array}$ & $\begin{array}{l}\text { No. Of Stocks In } \\
\text { The Portfolio }\end{array}$ & $\begin{array}{l}\text { Portfol } \\
\text { io } \beta\end{array}$ & $\begin{array}{l}\text { No. Of Stocks In } \\
\text { The Portfolio }\end{array}$ & $\begin{array}{l}\text { Portfol } \\
\text { io } \beta\end{array}$ \\
\hline 1 & 0.468 & 57 & 0.497 & 1 & -0.228 & 57 & 0.227 \\
\hline 2 & 0.453 & 58 & 0.499 & 2 & -0.211 & 58 & 0.231 \\
\hline 3 & 0.440 & 59 & 0.498 & 3 & -0.174 & 59 & 0.236 \\
\hline 4 & 0.348 & 60 & 0.501 & 4 & -0.140 & 60 & 0.240 \\
\hline 5 & 0.335 & 61 & 0.498 & 5 & -0.113 & 61 & 0.245 \\
\hline 6 & 0.370 & 62 & 0.501 & 6 & -0.094 & 62 & 0.249 \\
\hline 7 & 0.379 & 63 & 0.499 & 7 & -0.078 & 63 & 0.254 \\
\hline 8 & 0.395 & 64 & 0.502 & 8 & -0.066 & 64 & 0.258 \\
\hline 9 & 0.449 & 65 & 0.500 & 9 & -0.057 & 65 & 0.262 \\
\hline 10 & 0.450 & 66 & 0.498 & 10 & -0.046 & 66 & 0.267 \\
\hline 11 & 0.429 & 67 & 0.494 & 11 & -0.037 & 67 & 0.271 \\
\hline 12 & 0.393 & 68 & 0.491 & 12 & -0.029 & 68 & 0.275 \\
\hline 13 & 0.446 & 69 & 0.497 & 13 & -0.021 & 69 & 0.279 \\
\hline 14 & 0.438 & 70 & 0.492 & 14 & -0.015 & 70 & 0.284 \\
\hline 15 & 0.457 & 71 & 0.495 & 15 & -0.009 & 71 & 0.289 \\
\hline 16 & 0.432 & 72 & 0.503 & 16 & -0.003 & 72 & 0.294 \\
\hline 17 & 0.455 & 73 & 0.497 & 17 & 0.003 & 73 & 0.299 \\
\hline 18 & 0.455 & 74 & 0.500 & 18 & 0.009 & 74 & 0.304 \\
\hline 19 & 0.459 & 75 & 0.510 & 19 & 0.016 & 75 & 0.309 \\
\hline 20 & 0.478 & 76 & 0.512 & 20 & 0.024 & 76 & 0.314 \\
\hline 21 & 0.502 & 77 & 0.514 & 21 & 0.031 & 77 & 0.318 \\
\hline 22 & 0.526 & 78 & 0.509 & 22 & 0.038 & 78 & 0.323 \\
\hline 23 & 0.512 & 79 & 0.509 & 23 & 0.045 & 79 & 0.328 \\
\hline 24 & 0.526 & 80 & 0.511 & 24 & 0.052 & 80 & 0.332 \\
\hline 25 & 0.546 & 81 & 0.510 & 25 & 0.059 & 81 & 0.337 \\
\hline 26 & 0.559 & 82 & 0.504 & 26 & 0.065 & 82 & 0.341 \\
\hline
\end{tabular}




\begin{tabular}{|c|c|c|c|c|c|c|c|}
\hline 27 & 0.553 & 83 & 0.506 & 27 & 0.071 & 83 & 0.346 \\
\hline 28 & 0.547 & 84 & 0.503 & 28 & 0.077 & 84 & 0.350 \\
\hline 29 & 0.545 & 85 & 0.499 & 29 & 0.082 & 85 & 0.355 \\
\hline 30 & 0.536 & 86 & 0.500 & 30 & 0.088 & 86 & 0.360 \\
\hline 31 & 0.526 & 87 & 0.497 & 31 & 0.094 & 87 & 0.365 \\
\hline 32 & 0.504 & 88 & 0.490 & 32 & 0.099 & 88 & 0.370 \\
\hline 33 & 0.489 & 89 & 0.485 & 33 & 0.105 & 89 & 0.375 \\
\hline 34 & 0.499 & 90 & 0.480 & 34 & 0.110 & 90 & 0.380 \\
\hline 35 & 0.504 & 91 & 0.481 & 35 & 0.116 & 91 & 0.385 \\
\hline 36 & 0.500 & 92 & 0.484 & 36 & 0.121 & 92 & 0.390 \\
\hline 37 & 0.501 & 93 & 0.477 & 37 & 0.127 & 93 & 0.395 \\
\hline 38 & 0.490 & 94 & 0.484 & 38 & 0.133 & 94 & 0.400 \\
\hline 39 & 0.488 & 95 & 0.484 & 39 & 0.138 & 95 & 0.404 \\
\hline 40 & 0.493 & 96 & 0.482 & 40 & 0.144 & 96 & 0.409 \\
\hline 41 & 0.491 & 97 & 0.477 & 41 & 0.149 & 97 & 0.414 \\
\hline 42 & 0.492 & 98 & 0.481 & 42 & 0.154 & 98 & 0.420 \\
\hline 43 & 0.485 & 99 & 0.479 & 43 & 0.160 & 99 & 0.426 \\
\hline 44 & 0.492 & 100 & 0.485 & 44 & 0.165 & 100 & 0.431 \\
\hline 45 & 0.488 & 101 & 0.495 & 45 & 0.170 & 101 & 0.437 \\
\hline 46 & 0.486 & 102 & 0.498 & 46 & 0.175 & 102 & 0.443 \\
\hline 47 & 0.479 & 103 & 0.499 & 47 & 0.180 & 103 & 0.449 \\
\hline 48 & 0.494 & 104 & 0.507 & 48 & 0.185 & 104 & 0.454 \\
\hline 49 & 0.495 & 105 & 0.514 & 49 & 0.190 & 105 & 0.460 \\
\hline 50 & 0.487 & 106 & 0.509 & 50 & 0.195 & 106 & 0.466 \\
\hline 51 & 0.479 & 107 & 0.509 & 51 & 0.200 & 107 & 0.472 \\
\hline 52 & 0.469 & 108 & 0.509 & 52 & 0.204 & 108 & 0.479 \\
\hline 53 & 0.476 & 109 & 0.506 & 53 & 0.209 & 109 & 0.486 \\
\hline 54 & 0.474 & 110 & 0.504 & 54 & 0.213 & 110 & 0.493 \\
\hline 55 & 0.484 & 111 & 0.506 & 55 & 0.218 & 111 & 0.500 \\
\hline 56 & 0.493 & 112 & 0.509 & 56 & 0.222 & 112 & 0.509 \\
\hline
\end{tabular}

Table 6. Coefficients and model summary*

\begin{tabular}{|c|c|c|c|c|c|}
\hline \multirow{2}{*}{ Model } & \multicolumn{2}{|c|}{ Unstandardized Coefficients } & \multirow{2}{*}{$\begin{array}{l}\text { Standardized Coefficients } \\
\text { Beta }\end{array}$} & \multirow{3}{*}{$\begin{array}{l}\mathrm{T} \\
-6.420\end{array}$} & \multirow{3}{*}{$\begin{array}{l}\text { Sig } \\
\\
0.000\end{array}$} \\
\hline & $\mathrm{B}$ & Std.Error & & & \\
\hline Constant & -0.039 & 0.006 & & & \\
\hline $\mathrm{X}$ & 0.489 & 0.010 & 49.834 & 49.834 & 0.000 \\
\hline \multicolumn{6}{|l|}{ Multiple R } \\
\hline \multicolumn{6}{|l|}{0.9785} \\
\hline \multicolumn{6}{|c|}{$R^{2}$} \\
\hline \multicolumn{6}{|l|}{0.9575} \\
\hline \multicolumn{6}{|c|}{ Adjusted $R^{2}$} \\
\hline 0.9572 & & & & & \\
\hline
\end{tabular}




\section{Conclusion and Policy Implications}

The current study examined the relationship diversification and portfolio's beta. It has employed both of the Markwoitz and CAPM approaches for the 2005-2014 period. The empirical results attained through the comparison between the realized rate of return and the required rate of return that, most stocks in ASE are undervalued and have a realized rate of return lower than its required rate of return, which indicates to the inefficiency of ASE. Diversification can only affect unsystematic risk leaving systematic risk unaffected. The regression test indicated the existence of a significant relationship between the individual stock $\beta$ and the portfolio $\beta$ with a coefficient of determination of $(0.9575)$. As the number of stocks in the portfolio increases, the portfolio risk as measured by $\beta$ increases, if the new stock $\beta$ is higher than the portfolio $\beta$, on the other hand the portfolio $\beta$ decreases, if the new stock $\beta$ is lower than the portfolio $\beta$, which means that is no relationship between the portfolio size and portfolio $\beta$, and the portfolio $\beta$ is affected only by the individual stock $\beta$ value. As the portfolio size increases, we can maintain the stability of the portfolio $\beta$, by a greater proportion of constant $\beta$ stocks. The correlation analysis indicated that the relationship between the individual stock $\beta$ and the portfolio $\beta$ is nearly perfect positive correlation with a correlation coefficient of (0.979).

In the current study, we add to the existing literature by applying the CAPM in Jordan and fill the gap in the literature. In addition, the diversification is very important which has a huge impact on the portfolio riskiness, mainly on its specific risk, at which it can eliminate this risk to reach up to the systematic risk of the portfolio which known as $\beta$. This study is very important for different parties, like investors, whether they are individual or corporations, policymakers, ASE, and academic researchers. For investors, diversification is important to all equity investors and investors should take in consideration "when they diversify their portfolios" the portfolio unsystematic risk rather than the portfolio systematic risk. For policy makers, the study suggests cancelling the 5\% limit on the stock prices in the daily trading, and that's in order to improve the realized rate of return of the stocks. It's recommended for ASE to activate using short selling since stocks in the domestic market seem to be positively correlated. Therefore, short selling could be a practical tool in capturing most benefits of diversification and stabilize the volatility of the portfolio's return. Furthermore, ASE policies could be activating the bond market, where this market could be an additional investment tool for investors to improve their portfolio's performance. Eventually, the study recommends ASE policies to activate the other investment tools to hedge against risk, such as options, forwards, and futures.

\section{References}

Al Bakri, A. (2014). Portfolio Diversification Strategy and the Impacts on the Middle East Real Estate Investment Decision. International Journal of Economics and Finance, 6(2), 62.

Al-fayyoumi, N. (2003). Information Arrival, Trading Volume and Price Variability: An Applied Study on the Palestinian Securities Exchange. Yartmouk University Journal.

Al-Qudah, K., Al-Khouri, R., \& Ahmad, S. (2004). How Many Securities from a Well Diversified Portfolio in an Emerging Market (Developing Countries)? A Case Study of Amman Stock Exchange. Dirasat, Administrative Sciences, 31(1), 157-168.

Bekhet, H. A., \& Matar, A. (2012). Risk-adjusted performance: A two-model approach application in Amman stock exchange. International Journal of Business and Social Science, 3(7), 34-45.

Dicle, M. F., \& Khasawneh, A. Y. (2010). Do emerging markets offer diversification benefits? Case of Amman Stock Exchange.

Elsas, R., El-Shaer, M., \& Theissen, E. (2003). Beta and returns revisited: Evidence from the German stock market. Journal of International Financial Markets, Institutions and Money, 13(1), 1-18.

Frazzini, A., \& Pedersen, L. H. (2014). Betting against beta. Journal of Financial Economics, 111(1), 1-25.

Hassan, M. K., Maroney, N. C., El-Sady, H. M., \& Telfah, A. (2003). Country risk and stock market volatility, predictability, and diversification in the Middle East and Africa. Economic Systems, 27(1), 63-82.

Haugen, R. (2001). Modern Investment Theory (5th ed). Upper Saddle River. New Jersey: Prentice-Hall, Inc.

Kumar, A. (2007). Do the diversification choices of individual investors influence stock returns? Journal of Financial Markets, 10(4), 362-390.

Lau, S. C., Quay, S. R., \& Ramsey, C. M. (1974). The Tokyo Stock Exchange and the capital asset pricing model. Journal of Finance, 507-514.

Lintner, J. (1965a). Security Prices, Risk, and Maximal Gains from Diversification. Journal of Finance, 587-616. 
Maghyereh, A. I. (2003). The empirical relationship between expected return and risk in the Amman Stock Exchange.

Markowitz, H. (1952). Portfolio selection .The Journal of Finance, 7(1), 77-91.

Meric, I., Ratner, M., \& Meric, G. (2008). Co-movements of sector index returns in the world's major stock markets in bull and bear markets: Portfolio diversification implications. International Review of Financial Analysis, 17(1), 156-177.

Morelli, D. (2007). Beta, size, book-to-market equity and returns: A study based on UK data. Journal of Multinational Financial Management, 17(3), 257-272.

Odabaşı, A. (2003). Some Estimation Issues on Betas: A Preliminary Investigation on the Istanbul Stock Exchange. Unpublished working paper, Faculty of Economics and Administrative Sciences, Boğaziçi University, Istanbul, Turkey.

Omet, G., Khasawneh, M., \& Khasawneh, J. (2002). Efficiency tests and volatility effects: Evidence from the Jordanian stock market. Applied Economics Letters, 9(12), 817-821.

Omran, M. F. (2007). An analysis of the capital asset pricing model in the Egyptian stock market. The Quarterly Review of Economics and Finance, 46(5), 801-812.

Richard, J. C., \& Roncalli, T. (2015). Smart Beta: Managing Diversification of Minimum Variance Portfolios.

Sharpe, W. F. (1964). Capital asset prices: A theory of market equilibrium under conditions of risk. The journal of finance, 19(3), 425-442.

Tang, G. Y., \& Shum, W. C. (2003). The conditional relationship between beta and returns: Recent evidence from international stock markets. International Business Review, 12(1), 109-126.

Tang, G. Y., \& Shum, W. C. (2003). The relationships between unsystematic risk, skewness and stock returns during up and down markets. International Business Review, 12(5), 523-541.

Yalçın, A., \& Ersşahin, N. (2011). Does the conditional CAPM work? Evidence from the Istanbul Stock Exchange. Emerging Markets Finance and Trade, 47(4), 28-48.

\section{Copyrights}

Copyright for this article is retained by the author(s), with first publication rights granted to the journal.

This is an open-access article distributed under the terms and conditions of the Creative Commons Attribution license (http://creativecommons.org/licenses/by/4.0/). 